\title{
An Analysis of Occupational Health in Pork Production
}

\author{
Terrance M. Hurley, James B. Kliebenstein, and \\ Peter F. Orazem
}

\begin{abstract}
Data on attendees at the World Pork Expo from 1991-95 are used to evaluate the impact of farming generally, and hog farming and confinement operations more specifically, on the measured health outcomes of participants. Hog farming is found to increase risk of reduced hand strength and respiratory symptoms. To the extent these health risks are known, hog farmers will require a compensating differential to reward them for accepting a greater risk, an outcome consistent with higher long-term returns for hog production relative to cash-grain production.
\end{abstract}

Key words: occupational health, hog farming, control groups, compensating differential, rate of return.

Agricultural economists have focused on price and yield variability as the predominant sources of risk to farmers. Since hog production helps reduce income variability by smoothing the price and yield variability associated with grain production, returns to hog production should be lower than returns to cash-grain. However, long-run returns to hog production appear to dominate returns to cash-grain. ${ }^{1}$

An important source of risk that can potentially explain this apparent paradox is the differences in health risk faced by hog and cash-grain producers. Agriculture is second only to mining in risk of occupational death. Bureau of Labor Statistics data for 1995 show the work-related fatality rate for all industries was five deaths per 100 thousand workers, compared to twenty for agriculture and twenty-five for mining. Within agriculture, crop production had the highest death rate at thirty-five per 100 thousand, while the fatality

Terrance M. Hurley is an assistant professor in the Department of Applied Economics, University of Minnesota. James B. Kliebenstein and Peter F. Orazem are professors in the Department of Economics, Iowa State University.

The authors are grateful to Kelly Donham and Susanna Von Essen for useful comments at the early stages of this research and to the National Pork Producers Council for partial research support. Donna Otto and Cynthia Pease prepared the manuscript. This is Journal Paper No. J-17139 of the Iowa Agriculture and Home Economics Experiment Station, Ames, Iowa, Project No. 3235, supported by Hatch Act and State of Iowa funds.

${ }^{1}$ Iowa Farm Costs and Returns reports returns by farm type in Iowa between 1965 and 1995 averaged $10.2 \%$ for hog production and $7.9 \%$ for cash-grain production, with higher returns in hog production in two out of every three years. rate for livestock production was twelve per 100 thousand. Alternatively, livestock producers were more likely to experience nonfatal occupational injury, with 11.8 injuries per 100 full-time employees as compared to 8.8 for crop production. Almost half of all livestock injuries result in lost workdays costing U.S. agriculture an estimated $\$ 240$ million in 1995. ${ }^{2}$

There are a few studies of health risks in agricultural production. Most explore crop production and health outcomes for hired laborers. ${ }^{3}$ Less work has been done to understand important sources of occupational health risks for farm owners. In hog production, where a confinement facility with 25,000 hogs can produce as much effluent as a city with 50,000 people but in a much more concentrated area, farmers face substantial risk from increased exposure to dust, harmful gases, and animals. Some evidence of the occupational health risks associated with livestock production appears in the medical

\footnotetext{
${ }^{2}$ In 1995 , there were about 8,600 cases of injuries resulting in lost workdays in the livestock industry. The National Safety Council estimates an average cost of $\$ 28,000$ for injuries resulting in lost workdays. This cost includes lost wages, medical expenses, administrative expenses, and employer costs.

${ }^{3}$ A series of papers by Antle and Capalbo, Antle and Pingali, Crissman, Cole, and Carpio, and Pingali, Marquez, and Palis analyzes the risk of agricultural pesticide use in developing countries Davis, Caswell, and Harper and Harper and Zilberman considered how alternative institutional mechanisms promote worker safety and reduce risk related to pesticide use in the United States. One study that did not focus on pesticide use was by Frisvold, Mines, and Perloff, which considered how job sanitation affects the health of migrant farm workers.
} 
literature. ${ }^{4}$ However, these studies focus narrowly on swine producers and generally do not provide a comparison of health outcomes between hog farmers and control groups of other farmers or non-farmers.

Data collected at the World Pork Expo between 1991 and 1995 provide an opportunity to measure differences in occupational health risks between confinement hog producers, traditional hog producers, cash-grain farmers, and the population at large. The results indicate that farmers have a significantly greater incidence of hearing loss, weakened hand strength, and various respiratory symptoms, but have lower blood pressure than non-farmers with the same physical attributes. Hog producers report respiratory symptoms even more frequently than farmers do in general, but objective measures of lung capacity do not reveal any permanent loss of respiratory function.

To the extent hog producers are believed to face greater health risks than other farmers, those beliefs will have economic consequences. In particular, hog farmers will require a compensating differential in the form of higher returns in exchange for accepting these added perceived risks. Therefore, increased health risks associated with hog production can explain at least part of the higher average returns to hog production relative to cash-grain production.

\section{Health Production Functions}

The data for the analysis came from attendees of the World Pork Expo between 1991 and 1995. The World Pork Expo draws a wide range of industry stakeholders as well as members of the general public. A health pavilion was set up in which participants reported adverse health symptoms on a survey, which was followed by an objective health assessment administered by a qualified medical professional. The collection effort by the National Pork Producers Council (NPPC) was in response to concerns regarding occupational health and safety in the pork industry. As such, these data represent a unique opportunity to examine the incidence of occupational injury and health problems in the industry.

There are several advantages to this type of data. First, Expo attendees are broadly representative of hog producers; thus, the health

${ }^{4}$ For instance, see Donham et al. and Reynolds et al. measures should be broadly representative of health outcomes for farmers currently engaged in hog production. Second, it offers a large number of observations on hog producers generally and on confinement operators specifically. If more intensive hog production is associated with progressive deterioration in pulmonary function, for example, it may be evident only in large samples. On the other hand, adverse health outcomes commonly associated with hog farmers may be true of farmers more generally. The data allow this comparison. The sample of farmers who are not engaged in hog production allows us to estimate the increased occupational health risks faced by hog farmers generally or confinement operators specifically.

While the survey method used collected actual health data for a large number of participants, there are some methodological disadvantages that need to be remembered when interpreting results. First, the sample is predicated upon sufficient interest in the pork and associated industries to attend the Expo. Although this is not an issue for the sample of hog farmers, the non-hog farmers need not be representative of the population at large. Second, only individuals who were sufficiently interested in a voluntary free health evaluation were sampled. Moreover, the sample includes only those who felt well enough to travel to the Expo, so those with serious illnesses or debilitating injuries will be excluded. Therefore, the study will concentrate on the analysis of illnesses or injuries that may limit but not require abandonment of occupational pursuits in the pork industry. Furthermore, the sample is best suited for a general comparison of confinement against nonconfinement hog farmers and hog farmers against farmers more generally.

Another issue with the data is common in epidemiological analyses. Exposure to occupational hazards is predicated on selfselection into the occupation. Therefore, if an occupation involves exposure to known environmental contaminants, those remaining in the occupation will be disproportionately resistant to the occupational hazards. For example, asthma sufferers will be underrepresented in jobs involving exposure to dust such as hog production. As such, there will be a lower incidence of occupational illnesses exhibited in a sample of self-selected farm operators than would be true if individuals were randomly assigned to farming. As shown later, the availability of repeated 
observations for individuals who attended the Pork Expo two different years with continuous exposure to occupational hazards helps to correct for the potential self-selection bias.

\section{Empirical Strategies}

Health outcomes are viewed as a combination of $\mathbf{H}_{i t}$, human capital variables such as age, gender, and height, and predetermined individual choices with potential health consequences such as smoking or weight, and $\mathbf{O}_{i t}$, occupational variables that measure the presence of and intensity of exposure to job attributes that can enhance or diminish health outcomes. The production process can be described as

$$
h_{i t}=f\left(\mathbf{H}_{i t}, \mathbf{O}_{i t}, \mu_{i t}\right)
$$

where $h_{i t}$ is a measure of health for individual $i$ at time $t$ and $\mu_{i t}$ is an individual-specific health endowment.

Several measures of $h_{i t}$ were collected, some self-reported and others measured scientifically. Such data enable the assessment of whether damage has occurred and whether individuals perceive the damage. These comparisons can be made between perceived hearing loss and measured hearing loss and between perceived respiratory health and measured respiratory health. Objective measures of blood pressure and hand strength were also obtained.

The empirical health measures come in three different specifications, continuous variables, dichotomous variables, and ordered limited dependent variables. On the basis of the nature of the data, ordinary least squares, probit, or ordered probit regression is used. For individual $i$ at time $t$, the specifications take the form

$$
\begin{aligned}
h_{i t}= & \mathbf{H}_{i t} \boldsymbol{\gamma}_{\mathbf{H}}+D_{i t} \gamma_{D}+F_{i t} \gamma_{F} \\
& +F_{i t} P_{i t} \gamma_{P}+F_{i t} P_{i t} C_{i t} \mathbf{X}_{i t} \boldsymbol{\gamma}_{C}+\mu_{i t}
\end{aligned}
$$

where the vector of occupational attributes includes weekly hours of exposure to dust, $D_{i t}$; a dummy variable indicating farming occupation, $F_{i t}$; a dummy variable indicating hog farmer, $P_{i t}$; a dummy variable indicating confinement operator, $C_{i t}$; and a vector of confinement intensity measures, $\mathbf{X}_{i t}$, including a constant, years of confinement operation, and usual hours spent per week in a confinement building. Because all confinement operators in the data set are hog farmers and all hog farmers are farmers, this specification leads directly to tests of health outcomes between confinement operators relative to other hog farmers, hog farmers relative to other farmers, and farmers relative to non-farmers. For farmers, the health outcome for the average farmer $(F)$ relative to a nonfarmer $(N)$ with identical human capital attributes is

$$
\begin{aligned}
\bar{h}_{F}-\bar{h}_{N}= & \left(\bar{D}_{t}^{F}-\bar{D}_{t}^{N}\right) \gamma_{D}+\gamma_{F} \\
& +\bar{P}_{t}^{F} \gamma_{P}+\bar{P}_{t}^{F} \bar{C}_{t}^{F} \overline{\mathbf{X}}_{t}^{F} \boldsymbol{\gamma}_{C}
\end{aligned}
$$

where $\bar{D}_{t}^{F}$ is average weekly hours of dust exposure in farm operations, $\bar{D}_{t}^{N}$ is average dust exposure among non-farmers, $\bar{P}_{t}^{F}$ is the proportion of farmers with hog operations, and $\bar{C}_{t}^{F}$ is the proportion of farmers with confinement operations, and $\overline{\mathbf{X}}_{t}^{F}$ is the average intensity of exposure to confinement operation activities for farmers. ${ }^{5}$

Health effects for hog farmers $(P)$ differ from other farmers with identical human capital attributes according to

$$
\begin{aligned}
\bar{h}_{P}-\bar{h}_{F}= & \left(\bar{D}_{t}^{P}-\bar{D}_{t}^{F}\right) \gamma_{D} \\
& +\gamma_{P}+\bar{C}_{t}^{P} \overline{\mathbf{X}}_{t}^{P} \gamma_{C}
\end{aligned}
$$

where $\bar{D}_{t}^{P}$ is average weekly hours of dust exposure in hog production, $\bar{C}_{t}^{P}$ is the proportion of hog farmers with confinement operations, $\overline{\mathbf{X}}_{t}^{P}$ is the average intensity of exposure to confinement operation activities for hog farmers, and the other variables are defined as before.

Confinement operators' $(C)$ health effects differ from those of other hog farmers with identical human capital attributes according to

$$
\text { (5) } \bar{h}_{P}-\bar{h}_{P}=\left(\bar{D}_{t}^{C}-\bar{D}_{t}^{P}\right) \gamma_{D}+\overline{\mathbf{X}}_{t}^{C} \gamma_{C}
$$

where $\bar{D}_{t}^{C}$ is average weekly hours of dust exposure faced by confinement producers outside confinement buildings and $\overline{\mathbf{X}}_{t}^{C}$ is the average intensity of exposure to confinement operation activities for confinement producers. A Wald test is used to test the null hypotheses that equations (3), (4), and (5) are each equal to zero versus the alternative of differential health outcomes.

Differences in health outcomes between the $k$ th and $j$ th occupations are most easily interpreted in percentages rather than levels

\footnotetext{
${ }^{5}$ For these and all subsequent simulated health outcomes, the vector $\mathbf{H}$ is set at sample means, and occupational variables are measured at sample means for that occupation.
} 
because the units are not comparable across health outcomes. ${ }^{6}$ The percentage measures make it easier to interpret relative magnitudes of occupational health effects across indicators. For ordinary least square estimates, percentage differences in health outcomes between the $k$ th and $j$ th occupations are reported as

(6) $100 \times \frac{h_{k}\left(\overline{\mathbf{H}}, \overline{\mathbf{O}}_{k}\right)-h_{j}\left(\overline{\mathbf{H}}, \overline{\mathbf{O}}_{j}\right)}{h_{j}\left(\overline{\mathbf{H}}, \overline{\mathbf{O}}_{j}\right)}$

where the $h_{k}$ and $h_{j}$ are predicted health outcomes from equation (2) for individuals in occupations $k$ and $j$. The estimate holds fixed human capital attributes $\overline{\mathbf{H}}$ at the unconditional sample means, but the occupational attributes $\overline{\mathbf{O}}_{k}$ and $\overline{\mathbf{O}}_{j}$ are set at the occupation-specific sample means.

For the probit specifications, the percentage differences in health outcomes are reported as

$$
\begin{aligned}
& 100 \times[ F\left(-h_{k}\left(\overline{\mathbf{H}}, \overline{\mathbf{O}}_{k}\right)\right) \\
&\left.-F\left(-h_{j}\left(\overline{\mathbf{H}}, \overline{\mathbf{O}}_{j}\right)\right)\right] \\
& \quad / F\left(-h_{j}\left(\overline{\mathbf{H}}, \overline{\mathbf{O}}_{j}\right)\right)
\end{aligned}
$$

where $F(\cdot)$ is the cumulative normal distribution function. For the ordered probit estimates, the percentage differences for the $g$ th category are reported as

$$
\begin{gathered}
100 \times\left[F\left(\phi_{g}-h_{k}\left(\overline{\mathbf{H}}, \overline{\mathbf{O}}_{k}\right)\right)\right. \\
\left.-F\left(\phi_{g}-h_{j}\left(\overline{\mathbf{H}}, \overline{\mathbf{O}}_{j}\right)\right)\right] \\
/ F\left(\phi_{g}-h_{j}\left(\overline{\mathbf{H}}, \overline{\mathbf{O}}_{j}\right)\right) \\
\text { for } g=1 \\
100 \times\left\{\left[F\left(\phi_{g}-h_{k}\left(\overline{\mathbf{H}}, \overline{\mathbf{O}}_{k}\right)\right)\right.\right. \\
\left.-F\left(\phi_{g-1}-h_{k}\left(\overline{\mathbf{H}}, \overline{\mathbf{O}}_{k}\right)\right)\right] \\
/\left[F\left(\phi_{g}-h_{k}\left(\overline{\mathbf{H}}, \overline{\mathbf{O}}_{j}\right)\right)\right. \\
\left.-F\left(\phi_{g-1}-h_{k}\left(\overline{\mathbf{H}}, \overline{\mathbf{O}}_{j}\right)\right)\right] \\
-\left[F\left(\phi_{g}-h_{k}\left(\overline{\mathbf{H}}, \overline{\mathbf{O}}_{j}\right)\right)\right. \\
\left.-F\left(\phi_{g-1}-h_{k}\left(\overline{\mathbf{H}}, \overline{\mathbf{O}}_{j}\right)\right)\right]
\end{gathered}
$$

\footnotetext{
${ }^{6}$ For example, health outcomes are measured in blood pressure for one indicator, fluid volume in another, and probability of abnormal hearing in a third.
}

$$
\begin{gathered}
/\left[F\left(\phi_{g}-h_{k}\left(\overline{\mathbf{H}}, \overline{\mathbf{O}}_{j}\right)\right)\right. \\
\left.\left.-F\left(\phi_{g-1}-h_{k}\left(\overline{\mathbf{H}}, \overline{\mathbf{O}}_{j}\right)\right)\right]\right\} \\
\text { for } g>1 \text { and for } g<G-1 \\
100 \times\left[\left[1.0-F\left(\phi_{g-1}-h_{k}\left(\overline{\mathbf{H}}, \overline{\mathbf{O}}_{k}\right)\right)\right]\right. \\
\left.-\left[1.0-F\left(\phi_{g-1}-h_{k}\left(\overline{\mathbf{H}}, \overline{\mathbf{O}}_{j}\right)\right)\right]\right] \\
/ 1.0-F\left(\phi_{g-1}-h_{k}\left(\overline{\mathbf{H}}, \overline{\mathbf{O}}_{j}\right)\right) \\
\text { for } g=G-1
\end{gathered}
$$

where $G$ equals the number of categories, $\phi_{1}$ is normalized to 0 , and $\phi_{g}$ for $g=2, \ldots$, $G-1$ are estimated thresholds. Equations (6), (7), and (8) measure differences in health attributable to differences in occupation. In the tables that follow, the occupational health effects are reported in percentage form using (6)-(8), but the reported significance tests are from the Wald tests for the restrictions defined in equations (3)-(5).

As already indicated, these results are subject to self-selection bias. Individuals with large health endowments may be more willing to enter occupations with health risks. As a consequence, cross-sectional analysis will understate the true health consequences of risky occupations. A standard correction is to first-difference the data to eliminate the health endowment effect, provided longitudinal data on health outcomes are available.

Suppose that the individual-specific health component $\mu_{i t}$ can be decomposed into a time-invariant effect and a random error term so that $\mu_{i t}=\bar{\mu}_{i}+\xi_{i t}$. The first term, $\bar{\mu}_{i}$, is an individual's health endowment from birth, and the second term, $\xi_{i t}$, is a random error uncorrelated with the regressors in (2). First differencing health outcomes between years $t$ and $t+1$ results in

$$
\begin{aligned}
h_{i t+1}-h_{i t}= & \left(\mathbf{V}_{i t+1}-\mathbf{V}_{i t}\right) \gamma \\
& +\left(\xi_{i t+1}-\xi_{i t}\right)
\end{aligned}
$$

where $\mathbf{V}_{i t}$ is the vector of human capital and occupational variables for individual $i$ at time $t$ and $\gamma$ is the vector of parameters, $\left(\gamma_{N}, \gamma_{D}, \gamma_{F}, \gamma_{P}, \gamma_{C}\right)^{\prime}$. First differencing eliminates the individual fixed effect from the regression. In addition, most of these variables (smoking, sex, height, weight, and occupation) do not change over time, so the only components in $\mathbf{V}_{i t+1}-\mathbf{V}_{i t}$ are changes in age 
and length of time in confinement. Therefore, the empirical formulation for (9) is

$$
\begin{aligned}
h_{i t+1}-h_{i t}= & (\Delta \text { Age }) \gamma_{A} \\
& +(\Delta \text { Confinment Yrs. }) \gamma_{C} \\
& +\left(\xi_{i t+1}-\xi_{i t}\right) .
\end{aligned}
$$

In the results that follow, we allow the age effect on health to differ between farmers, hog farmers, and confinement hog farmers. In equation (10), this sets $\gamma_{A}=\gamma_{A}^{F}+\gamma_{A}^{P} P+\gamma_{A}^{C} C$, where $P$ is a dummy variable designating hog farmers and $C$ is a dummy variable designating confinement hog farmers.

\section{Results}

Summary statistics including conditional means for the explanatory variables are presented in table 1 . Over the five-year period, there were 1,140 observations with complete information for all of the explanatory variables. Sample statistics are reported separately by self-reported occupational status. Respondents were asked to indicate if they were farmers or not. Farmers were asked to indicate how many years they had spent in hog farming or confinement hog farming, and how many hours per week they spent in confinement facilities. All respondents were asked how many hours per week they spent in dusty environments. Farmers who reported positive hours per week in a confinement operation were placed in the confinement group. Farmers who had experience in the pork industry but not in the confinement were placed in the hog farmer group. Farmers with no experience in the pork industry were placed in the farmer group, and everyone else made up the nonfarmers.

Smokers represented $28 \%$ of the sample. The average age was forty-two years. Three-fourths of the respondents were male. The average height was 69 inches with an average weight of 186 pounds. About $9 \%$ of the respondents reported being employed outside of farming. Of the $91 \%$ that reported being farmers, $27 \%$ were nonconfinement hog farmers, while $63 \%$ were confinement hog farmers. In terms of age, height, and weight, the sub-samples were relatively homogeneous, with the slightly higher height and weight for confinement hog farmers most likely attributable to the higher proportion of males. Confinement farmers averaged just less than thirteen years in confinement and spent twenty-one hours a week in confinement buildings. Confinement hog farmers spent more time in dusty environments than did other hog farmers, farmers, or non-farmers. However, hog farmers were also more likely to smoke than farmers or non-farmers. Therefore, it is possible that differences in average health outcomes between hog farmers and others could be attributable to smoking rather than to unsafe environments, an issue that is addressed in the comparative static analysis below.

The bottom of table 1 reports descriptive statistics for the various health indicators. The table reveals several health indicators that seem markedly worse for hog farmers than either other farmers or nonfarmers. Hog farmers have more problems with hand strength and various respiratory symptoms such as cough and phlegm and cold or flu symptoms. However, the descriptive statistics also demonstrate why it is important to have populations of other farmers against which to compare hog farmer health outcomes. For example, a high proportion of hog farmers is diagnosed with impaired hearing, but the same is true of farmers who do not raise hogs. On the other hand, farmers had more than double the rate of hearing impairment as non-farmers, suggesting that the hearing injuries may be related to farming generally, but not hog farming specifically. Once again, it is important to emphasize that these comparisons do not hold constant other differences between hog farmers, other farmers, and non-farmers that might also explain these health outcomes.

\section{Comparative Static Analysis}

Tables 2 and 3 report the results of the health production functions. As already discussed, bivariate or ordered probit analyses were used to explain discretely measured health outcomes, whereas continuous measures of health outcomes were analyzed using ordinary least squares. The human capital effects, smoking, age, gender, height, and weight, are included to establish a population norm against which farmer health can be assessed, but not reported since our discussion will concentrate on occupational health effects. ${ }^{7}$ The estimated marginal impacts of

\footnotetext{
${ }^{7} \mathrm{~A}$ full set of regression results is available on request.
} 
Table 1. Descriptive Statistics for the (a) Explanatory Variables and (b) Dependent Variables

(a)

\begin{tabular}{lccccc}
\multicolumn{1}{c}{ Explanatory Variables } & $\begin{array}{c}\text { All } \\
\text { Respondents }\end{array}$ & $\begin{array}{c}\text { Non- } \\
\text { Farmers }\end{array}$ & Farmers & $\begin{array}{c}\text { Hog } \\
\text { Farmers }\end{array}$ & $\begin{array}{c}\text { Confinement } \\
\text { Hog Farmers }\end{array}$ \\
\hline Percent smokers & 28 & 17 & 24 & 25 & 32 \\
Age & 41.51 & 43.32 & 44.00 & 43.16 & 40.11 \\
& $(12.38)^{\mathrm{a}}$ & $(14.72)$ & $(15.04)$ & $(12.92)$ & $(11.05)$ \\
Percent male & 77 & 60 & 68 & 65 & 86 \\
Height (inches) & 69.10 & 68.21 & 68.23 & 68.15 & 69.78 \\
& $(3.38)$ & $(3.95)$ & $(3.95)$ & $(3.67)$ & $(2.87)$ \\
Weight (lbs) & 185.55 & 181.01 & 178.82 & 182.05 & 188.84 \\
& $(34.40)$ & $(38.64)$ & $(36.01)$ & $(35.32)$ & $(32.69)$ \\
Weekly hours in & 6.28 & 1.51 & 4.80 & 6.00 & 7.38 \\
dusty environment & $(9.85)$ & $(4.96)$ & $(9.69)$ & $(9.34)$ & $(10.40)$ \\
Weekly hours in & 12.16 & & & & 21.20 \\
confinement building & $(16.91)$ & & & & $(17.51)$ \\
Years in confinement & 7.34 & & & & 12.79 \\
farming & $(8.68)$ & & & & $(7.85)$ \\
Observations & 1140 & 102 & 105 & 279 & 654 \\
\hline
\end{tabular}

(b)

Dependent Variables

All Non- Hog Confinement Respondents Farmers Farmers Farmers Hog Farmers

\begin{tabular}{|c|c|c|c|c|c|}
\hline $\begin{array}{l}\text { Percent experiencing } \\
\text { hearing problems }\end{array}$ & 59 & 36 & 47 & 57 & 66 \\
\hline $\begin{array}{l}\text { Percent diagnosed with } \\
\text { left ear abnormal }\end{array}$ & 32 & 18 & 40 & 34 & 33 \\
\hline $\begin{array}{l}\text { Percent diagnosed as } \\
\text { hearing impaired }\end{array}$ & 53 & 21 & 57 & 57 & 58 \\
\hline Dynamometer dominant hand strength $\mathrm{b}$ & 1.83 & 2.47 & 1.96 & 1.78 & 1.77 \\
\hline $\begin{array}{l}\text { Percent recommended for } \\
\text { hand strength followup }\end{array}$ & 18 & 3 & 16 & 19 & 20 \\
\hline Systolic blood pressure & 124 & 126 & 123 & 124 & 125 \\
\hline Diastolic blood pressure & 75 & 77 & 74 & 75 & 75 \\
\hline Percent reporting cough/phlegm & 30 & 14 & 19 & 29 & 33 \\
\hline Percent reporting flu symptoms & 30 & 14 & 22 & 27 & 33 \\
\hline $\begin{array}{l}\text { Percent reporting worse } \\
\text { symptoms after a brief } \\
\text { absence from work }\end{array}$ & 17 & 16 & 16 & 12 & 19 \\
\hline Forced vital capacity (FVC) & 4.57 & 4.28 & 4.20 & 4.25 & 4.80 \\
\hline $\begin{array}{l}\text { Percent diagnosed with } \\
\text { normal respiration }\end{array}$ & 84 & 80 & 87 & 82 & 84 \\
\hline Change in FVC & 0.15 & 0.14 & 0.32 & 0.12 & 0.14 \\
\hline
\end{tabular}

a Standard deviations are in parentheses.

${ }^{\mathrm{b}} 0=$ first quartile, $1=$ second quartile, $2=$ third quartile, and $3=$ fourth quartile.

farming, hog farming, and confinement hog farming on health indicators from equations (3)-(8) are reported at the bottom of each table.

Table 2 reports the analysis of self-reported and objective measures of hearing and hand strength. Farmers reported experiencing tinnitus, temporary loss of hearing, or headaches significantly more often than non-farmers. Farmers were over twice as likely as nonfarmers to have objective hearing evaluations reveal abnormalities in the left ear, and over three times more likely than non-farmers to be judged as hearing impaired. ${ }^{8}$ While hog farmers and confinement hog farmers reported a statistically significant higher incidence of self-reported hearing problems relative to other farmers, the magnitude of the effect is very small. Furthermore, objective

\footnotetext{
${ }^{8}$ Similar results were found for the right ear and are available on request.
} 
Table 2. Probit and Ordered Probit Analysis of Self-reported Hearing and Objective Measures of Hearing and Hand Strength

\begin{tabular}{|c|c|c|c|c|c|c|c|c|c|}
\hline & \multirow{2}{*}{$\begin{array}{c}\text { Self-Reported } \\
\text { Hearing } \\
\text { Problems }^{\mathrm{d}}\end{array}$} & \multicolumn{8}{|c|}{ Objective } \\
\hline & & $\begin{array}{c}\text { Left ear } \\
\text { abnormal }^{\mathrm{d}}\end{array}$ & $\begin{array}{c}\text { Hearing } \\
\text { Impaired }^{\mathrm{d}}\end{array}$ & & & $\begin{array}{l}\text { Dominant } \\
\text { Hand }^{\mathrm{c}}\end{array}$ & & & $\begin{array}{c}\text { Hand } \\
\text { Follow-up }\end{array}$ \\
\hline \multirow{4}{*}{$\begin{array}{l}\text { Weekly hours in } \\
\text { dusty environment } \\
\text { Framer }\end{array}$} & 0.014 & 0.0039 & -0.006 & & & 0.0081 & & & 0.0047 \\
\hline & $(3.14)^{\mathrm{a}}$ & $(0.90)$ & $(0.12)$ & & & $(1.41)$ & & & $(0.74)$ \\
\hline & 0.21 & 0.84 & 1.10 & & & -0.25 & & & 0.96 \\
\hline & $(1.20)$ & $(3.89)^{\mathrm{a}}$ & $(4.69)^{\mathrm{a}}$ & & & $(0.83)$ & & & $(2.60)^{\mathrm{a}}$ \\
\hline \multirow[t]{2}{*}{ Pig farmer } & 0.23 & -0.14 & 0.082 & & & -0.38 & & & 0.12 \\
\hline & $(1.57)$ & $(0.88)$ & $(0.44)$ & & & $(2.13)^{b}$ & & & $(0.55)$ \\
\hline \multirow[t]{2}{*}{ Confinement farmer } & 0.24 & -0.14 & 0.14 & & & -0.11 & & & 0.40 \\
\hline & $(1.57)$ & $(0.86)$ & $(0.67)$ & & & $(0.55)$ & & & $(1.77)^{\mathrm{c}}$ \\
\hline \multirow{5}{*}{$\begin{array}{l}\text { Weekly hours in } \\
\text { confinement building } \\
\text { Years in confinement } \\
\text { farming } \\
\text { Ordered probit } \\
\text { thresholds }\end{array}$} & 0.0044 & 0.0020 & -0.0008 & & & -0.0014 & & & 0.0031 \\
\hline & $(1.45)$ & $(0.63)$ & $(0.21)$ & & & $(0.40)$ & & & $(0.76)$ \\
\hline & -0.0073 & 0.0078 & -0.0044 & & & 0.010 & & & -0.015 \\
\hline & $(1.04)$ & $(1.03)$ & $(0.47)$ & & & $(1.06)$ & & & $(1.49)$ \\
\hline & & & & & $\begin{array}{c}0.723 \\
(11.03)^{\mathrm{a}}\end{array}$ & & $\begin{array}{c}1.577 \\
(19.12)^{\mathrm{a}}\end{array}$ & & \\
\hline \multirow{3}{*}{$\begin{array}{l}\text { (Pseudo) R-squared } \\
\text { Log-likelihood } \\
\text { Observations }\end{array}$} & 0.05 & 0.17 & 0.22 & & & 0.07 & & & 0.08 \\
\hline & -731.11 & -593.52 & -420.63 & & & -646.45 & & & -290.31 \\
\hline & 1140 & 1140 & 784 & & & 520 & & & 678 \\
\hline \multirow[t]{2}{*}{ Farm vs. non-farm } & $67.74 \%$ & $186.85 \%$ & $278.72 \%$ & $\begin{array}{c}\text { First Quartile } \\
169.64 \%\end{array}$ & $\begin{array}{c}\text { Second Quartile } \\
66.14 \%\end{array}$ & & $\begin{array}{c}\text { Third Quartile } \\
9.02 \%\end{array}$ & $\begin{array}{c}\text { Fourth Quartile } \\
-41.81 \%\end{array}$ & $1,073.40 \%$ \\
\hline & $(22.52)^{\mathrm{a}}$ & $(17.62)^{\mathrm{a}}$ & $(43.38)^{\mathrm{a}}$ & & & $(4.23)^{\mathrm{b}}$ & & & $(14.50)^{\mathrm{a}}$ \\
\hline \multirow[t]{2}{*}{ Hog farm vs. farm } & $2.61 \%$ & $-1.54 \%$ & $0.87 \%$ & $5.89 \%$ & $2.36 \%$ & & $-0.46 \%$ & $-4.30 \%$ & $4.65 \%$ \\
\hline & $(10.45)^{\mathrm{a}}$ & $(0.85)$ & $(0.55)$ & & & $(5.15)^{b}$ & & & $(2.53)$ \\
\hline Confinement hog & $4.45 \%$ & $0.14 \%$ & $1.25 \%$ & $-0.04 \%$ & $-0.02 \%$ & & $0.00 \%$ & $0.03 \%$ & $11.94 \%$ \\
\hline Farm vs. hog farm & $(7.29)^{\mathrm{a}}$ & $(0.00)$ & $(0.24)$ & & & $(0.00)$ & & & $(3.53)^{\mathrm{c}}$ \\
\hline
\end{tabular}

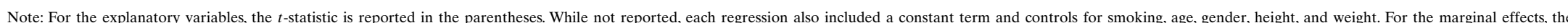

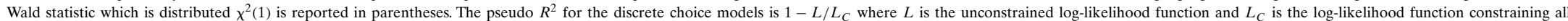
slope coefficients to zero.

${ }^{a}$ Significant at $1 \%$.

${ }^{\mathrm{b}}$ Significant at $5 \%$.

${ }^{c}$ Significant at $10 \%$

d Probit analysis.

e Ordered probit analysis with first threshold normalized to 0.0 . 
Table 3. Probit and Ordinary Least Square Analysis of Blood Pressure, Self-reported Respiratory Health, and Objective Respiratory Health Measures

\begin{tabular}{|c|c|c|c|c|c|c|c|c|}
\hline & \multicolumn{2}{|c|}{ Blood Pressure } & \multicolumn{3}{|c|}{ Self-Reported Respiratory Health } & \multicolumn{3}{|c|}{ Objective Respiratory Health } \\
\hline & Systolic $^{\mathrm{e}}$ & Diastolic $^{\mathrm{e}}$ & $\begin{array}{l}\text { Cough/ } \\
\text { Phlegm }^{\mathrm{d}}\end{array}$ & $\begin{array}{c}\text { Flu } \\
\text { Symptoms }^{\mathrm{d}}\end{array}$ & $\begin{array}{l}\text { Absence } \\
\text { Effect }^{\mathrm{d}}\end{array}$ & $\mathbf{F V C}^{\mathrm{e}}$ & $\begin{array}{l}\text { Respiration } \\
\text { Normal }^{\mathrm{d}}\end{array}$ & $\begin{array}{c}\text { Change in } \\
\text { FVC }^{\mathrm{e}}\end{array}$ \\
\hline $\begin{array}{l}\text { Weekly hours in } \\
\text { dusty environment }\end{array}$ & $\begin{array}{r}0.037 \\
(0.88)\end{array}$ & $\begin{array}{c}0.028 \\
(0.93)\end{array}$ & $\begin{array}{l}0.0034 \\
(0.77)\end{array}$ & $\begin{array}{c}0.012 \\
(2.93)^{\mathrm{a}}\end{array}$ & $\begin{array}{l}0.0083 \\
(1.79)^{\mathrm{c}}\end{array}$ & $\begin{array}{l}0.0010 \\
(0.48)\end{array}$ & $\begin{array}{l}-0.0027 \\
(0.49)\end{array}$ & \\
\hline Farmer & $\begin{array}{c}-2.63 \\
(1.39)\end{array}$ & $\begin{array}{l}-2.76 \\
(2.04)^{b}\end{array}$ & $\begin{array}{c}0.28 \\
(0.76)\end{array}$ & $\begin{array}{c}0.33 \\
(1.10)\end{array}$ & $\begin{array}{r}-0.013 \\
(0.04)\end{array}$ & $\begin{array}{c}-0.14 \\
(1.54)\end{array}$ & $\begin{array}{c}0.36 \\
(1.46)\end{array}$ & $\begin{array}{r}0.075 \\
(0.38)\end{array}$ \\
\hline Pig farmer & $\begin{array}{c}0.46 \\
(0.30)\end{array}$ & $\begin{array}{c}0.10 \\
(0.09)\end{array}$ & $\begin{array}{c}0.32 \\
(1.69)^{\mathrm{c}}\end{array}$ & $\begin{array}{c}0.16 \\
(0.93)\end{array}$ & $\begin{array}{c}-0.17 \\
(0.84)\end{array}$ & $\begin{array}{r}0.054 \\
(0.71)\end{array}$ & $\begin{array}{c}-0.29 \\
(1.35)\end{array}$ & $\begin{array}{c}-0.13 \\
(0.73)\end{array}$ \\
\hline Confinement farmer & $\begin{array}{l}-0.45 \\
(0.29)\end{array}$ & $\begin{array}{l}-2.29 \\
(2.02)^{\mathrm{b}}\end{array}$ & $\begin{array}{r}-0.12 \\
(0.72)\end{array}$ & $\begin{array}{c}-0.26 \\
(1.60)\end{array}$ & $\begin{array}{c}-0.044 \\
(0.23)\end{array}$ & $\begin{array}{l}0.0013 \\
(0.02)\end{array}$ & $\begin{array}{l}0.0042 \\
(0.02)\end{array}$ & $\begin{array}{r}0.043 \\
(0.48)\end{array}$ \\
\hline $\begin{array}{l}\text { Weekly hours in } \\
\text { confinement building } \\
\text { Years in confinement } \\
\text { farming }\end{array}$ & $\begin{array}{c}0.057 \\
(1.84)^{\mathrm{c}} \\
-0.103 \\
(1.40)\end{array}$ & $\begin{array}{c}0.042 \\
(1.89)^{\mathrm{c}} \\
0.076 \\
(1.41)\end{array}$ & $\begin{array}{c}-0.0002 \\
(0.06) \\
0.013 \\
(1.68)^{\mathrm{c}}\end{array}$ & $\begin{array}{c}0.0056 \\
(1.84)^{\mathrm{c}} \\
0.018 \\
(2.48)^{\mathrm{b}}\end{array}$ & $\begin{array}{c}0.0063 \\
(1.86)^{\mathrm{c}} \\
0.018 \\
(2.09)^{\mathrm{b}}\end{array}$ & $\begin{array}{l}0.0003 \\
(0.19) \\
0.0057 \\
(1.57)\end{array}$ & $\begin{array}{c}-0.0007 \\
(0.16) \\
0.012 \\
(1.25)\end{array}$ & \\
\hline $\begin{array}{l}\text { (Pseudo) R-squared } \\
\text { Log-likelihood } \\
\text { Observations }\end{array}$ & $\begin{array}{r}0.20 \\
-4,563.65 \\
1136\end{array}$ & $\begin{array}{r}0.14 \\
-4,169.70 \\
1132\end{array}$ & $\begin{array}{r}0.02 \\
-543.49 \\
901\end{array}$ & $\begin{array}{r}0.03 \\
-601.17 \\
1023\end{array}$ & $\begin{array}{r}0.04 \\
-426.80 \\
976\end{array}$ & $\begin{array}{r}0.61 \\
-1,114.75 \\
1116\end{array}$ & $\begin{array}{r}0.02 \\
-344.71 \\
786\end{array}$ & $\begin{aligned}-0.01 \\
-162.59 \\
132\end{aligned}$ \\
\hline Farm vs. non-farm & $\begin{array}{c}-1.87 \% \\
(2.78)^{\mathrm{c}}\end{array}$ & $\begin{array}{c}-3.60 \% \\
(7.53)^{\mathrm{a}}\end{array}$ & $\begin{array}{c}136.91 \% \\
(3.40)^{\mathrm{c}}\end{array}$ & $\begin{array}{c}134.28 \% \\
(5.14)^{\mathrm{b}}\end{array}$ & $\begin{array}{l}12.93 \% \\
(0.08)\end{array}$ & $\begin{array}{c}-0.83 \% \\
(0.30)\end{array}$ & $\begin{array}{l}5.65 \% \\
(1.06)\end{array}$ & \\
\hline Hog farm vs. farm & $\begin{array}{l}0.01 \% \\
(0.01)\end{array}$ & $\begin{array}{c}-0.02 \% \\
(0.02)\end{array}$ & $\begin{array}{c}4.26 \% \\
(4.17)^{\mathrm{b}}\end{array}$ & $\begin{array}{l}3.08 \% \\
(2.59)\end{array}$ & $\begin{array}{l}1.10 \% \\
(0.16)\end{array}$ & $\begin{array}{l}0.25 \% \\
(2.67)\end{array}$ & $\begin{array}{c}-0.56 \% \\
(0.97)\end{array}$ & \\
\hline $\begin{array}{l}\text { Confinement hog } \\
\text { Farm vs. hog farm }\end{array}$ & $\begin{array}{l}-0.12 \% \\
(0.25)\end{array}$ & $\begin{array}{l}-0.16 \% \\
(0.29)\end{array}$ & $\begin{array}{l}1.70 \% \\
(0.22)\end{array}$ & $\begin{array}{l}3.99 \% \\
(1.25)\end{array}$ & $\begin{array}{l}15.61 \% \\
(6.88)^{\mathrm{a}}\end{array}$ & $\begin{array}{l}0.54 \% \\
(2.74)^{\mathrm{c}}\end{array}$ & $\begin{array}{l}1.21 \% \\
(1.09)\end{array}$ & \\
\hline
\end{tabular}

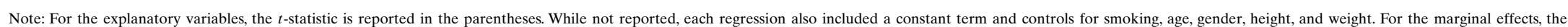

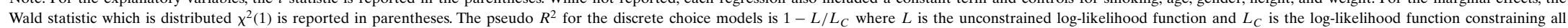
slope coefficients to zero.

a Significant at $1 \%$.

Significant at $5 \%$.

Significant at $10 \%$

d Probit analysis.

e Ordinary least square analysis 
hearing tests did not reveal an increased incidence of abnormalities beyond those experienced by farmers in general. Therefore, decreased hearing from occupational health risk seems to be attributable to working conditions experienced by all farmers and not to working conditions associated with hog production. A reasonable explanation for these hearing problems is exposure to noise from livestock and machinery used in livestock and/or grain production.

The remaining columns of table 2 present the results of hand strength tests. The hand strength measures were coded in quartiles with the highest quartile representing the top $25 \%$ in the population. Farmers were $170 \%$ more likely than non-farmers to be in the lowest quartile for hand strength and were $66 \%$ more likely to be in the second lowest quartile. Farmers were eleven times more likely than non-farmers with the same human capital attributes to be diagnosed as needing additional tests. ${ }^{9}$ Hog farmers had even more evidence of weakened hand strength in the dominant hand. Unreported tests found no evidence of weaker hand strength in the nondominant hand, suggesting the loss of strength is attributable to work and not illness or hazards that would affect both hands. Hog farmers were $4.6 \%$ more likely to be referred for additional tests than were other farmers, with some evidence of an even higher probability of referrals for confinement farmers. Loss of hand strength associated with farming occurs even though farming might have been viewed as more physically demanding and populated by relatively strong individuals. The root cause for the reduced hand strength would require additional research, but carpal tunnel syndrome or other injuries associated with repetitive movements would be likely candidates for this occupational injury. Farmers may also have a greater exposure to debilitating hand injuries than non-farmers.

The first two columns of table 3 present the analysis of blood pressure tests. Here, the story for farming is better. Farmers have lower blood pressure, other things equal, although the effect is relatively small. Systolic blood pressure is about $2 \%$ lower, and diastolic blood pressure is $3.6 \%$ lower for farmers than for non-farmers with the same age, gender, stature, and smoking habits. These differences in blood pressure are not large

${ }^{9}$ Results for non-dominant hand tests are available on request. enough to draw any major conclusion, but it does seem that farmers benefit from their active occupation relative to more sedentary work. Blood pressure for hog farmers or confinement operators did not differ significantly from that of other farmers.

The middle columns of table 3 report results of the self-reported assessments of respiratory health. The self-reported measures include questions regarding recurrent congestion or flu-like symptoms. In addition, farmers were asked if exposure to the hog operation after a period of absence (two days) resulted in heightened symptoms. Farmers were more than twice as likely as non-farmers to report recurrent cough and flu symptoms. Hog farmers were more likely than other farmers to report cough symptoms. Confinement operators had symptoms similar to those of other hog farmers except they were more likely to report a worsening of symptoms after a two-day absence. Increased incidence of self-reported symptoms was expected particularly for confinement hog farmers since they are exposed to dust and gas from animal feed and waste in an enclosed work environment. Interestingly, traditional hog farmers appear to suffer from these types of exposure nearly as much.

The self-reported assessments can be viewed as nagging problems, which may make life less pleasant. It is not clear if recurrent cough or flu symptoms will result in permanent disability. The issue of chronic pulmonary problems is addressed in the last three columns of table 3 . Forced vital capacity (FVC) is a measure of lung capacity. Despite the higher incidence of reported symptoms associated with farming and hog farming, there is no evidence of reduced lung capacity that might signal permanent disabling occupational disease. Indeed, hog farming and confinement hog farming were associated with marginally greater lung capacity. When compared with population norms for individuals of the same gender, age, and stature, hog farmers had lung capacity within the normal ranges.

It is possible that the lack of an adverse effect of hog production on lung capacity is due to self-selection into the pork industry. Those with asthma or other predispositions to respiratory problems do not go into hog production, so hog farmers have disproportionately large lung capacity when they enter the industry. In fact, the average lung capacity of confinement hog farmers in table 1 
is much greater than that of other farmers. Therefore, even if hog production is associated with diminishing respiratory function over time, the adverse effect may be masked in cross sections. The effect is similar to that of smoking. Smoking is associated with significantly greater lung capacity in the sample, even though it is known that smoking reduces lung capacity over time. As Miller has shown, smokers tend to have atypically large lung capacity in the early years of smoking because asthmatics, allergy sufferers, and others with poor respiratory health endowments never smoke. The true adverse effect of smoking on respiratory health is evident only in longitudinal data for which the respiratory health endowment can be first differenced away.

There were lung capacity observations from two different years for 132 individuals. Using equation (10), the individual fixed health effect was differenced away, and observations were made on how confinement operations affect the change in lung capacity over time. As the results in the last column of table 3 show, hog farmers and confinement hog farmers have reduced lung capacity from continuous exposure, but the coefficients are very small and not significant. These results support the conclusions based on the cross-sectional data that hog production does not seem to reduce pulmonary function for Expo attendees.

The contrast between adverse self-reported respiratory health outcomes and the neutral health outcomes that are objective may be a consequence of the relatively short period over which the objective pulmonary function measures are taken. The temporary symptoms reported in table 3 may signal a more permanent disability if damage to lung capacity becomes known only after years of exposure to environmental contaminants associated with hog production. Most of the longitudinal observations are one or two years apart, which may be too short a period to observe significant adverse pulmonary effects. Additionally, those most severely affected may no longer be attending the Expo. If exposure over several years or even decades is necessary for permanent health effects to occur, then a much longer-term investigation of pulmonary function is required.

It is difficult to assess whether the risk of adverse health outcomes affects the decision to enter hog production. However, there is evidence that adverse health outcomes have caused exits from hog farming. A longitudinal study of Canadian swine producers (Holness et al.) found that $15 \%$ exited over a six-year period due to respiratory problems. In Iowa, $34 \%$ of the farmers under 40 who exited hog farming listed health as a very important factor in the exit decision, compared to $42 \%$ who listed insufficient return on investment as very important. ${ }^{10}$ Of those who indicated that health was an important consideration in their decision to leave hog farming, 93\% continued in other farming enterprises, suggesting that health concerns were related to hog farming specifically and not to farming in general. Therefore, health concerns do limit the number of farmers involved in hog production as opposed to farming more generally, consistent with the stylized fact of higher returns to hog production. ${ }^{11}$

\section{Conclusions}

Iowa cost and returns data from the past three decades indicate hog farmers earn a greater return on their investment than cash-grain producers, even though diversified hog farmers should face lower price and production risk than less diversified cashgrain producers. One potential explanation for this higher return is that hog farmers face increased occupational health risks. Data from the World Pork Expo between 1991 and 1995 reveal significantly higher risk of reduced hand strength, flu, throat irritation, sinus, and cough symptoms. In general, confinement farmers do not appear to suffer significant short-term adverse health consequences beyond those experienced by more traditional hog farmers. However, future work will need to follow farmers for a longer period of time to determine if there are long-term health consequences from hog production in general and confinement hog production specifically.

If hog farmers face occupational hazards beyond those faced by other farmers, is government intervention in farm safety warranted? If health risks associated with hog production are known, then farmers who choose hog production should either be less risk averse or have a comparative advantage

\footnotetext{
${ }^{10}$ This information comes from the authors' analysis of 1997 survey data provided by John Lawrence.

${ }^{11}$ Corroborating evidence that adverse health consequences from hog production require a compensating differential can be found in wages paid to employees on hog farms. Hurley, Orazem, and Kliebenstein found that employees working in hog production are paid higher wages in operations with inferior working conditions, holding skill and other factors constant.
} 
in absorbing the health risks. Hersch and Viscusi found that attitudes toward health risks matter in occupational choice: people who take more health risks outside of work (people who smoke and who do not wear seatbelts were viewed as taking more risks) were more willing to accept occupational health risks as well. Physical abilities to absorb risks also seem to matter. That confinement farmers are both more likely to smoke and have greater lung capacity than other farmers is consistent with informed sorting. Confinement operators are apparently less risk averse and more able to absorb airborne occupational hazards than are farmers who opt not to raise hogs. A definite test would require a time series of successive cohorts of young farmers to see if changes in perceived occupational hazards alter the choice of operation type. This would also allow evaluation of the health status of farmers over time. Such a study would be a unique contribution to the study of occupational choice. ${ }^{12}$

\section{[Received December 1996; accepted April 1999.]}

\section{References}

Antle, J.M., and P.L. Pingali. "Pesticides, Productivity, and Farmer Health: A Philippine Case Study." Amer. J. Agr. Econ. 76(August 1994):418-30.

Antle, J.M., and S.M. Capalbo. "Pesticides, Productivity, and Farmer Health: Implications for Regulatory Policy and Agricultural Research." Amer. J. Agr. Econ. 76(August 1994):598-602.

Crissman, C.C., D.C. Cole, and F. Carpio. "Pesticides Use and Farm Worker Health in Ecuadorian Potato Production." Amer. J. Agr. Econ. 76(August 1994):593-97.

\footnotetext{
${ }^{12}$ There are a few studies of the impact of financial risk on occupational choice. For example, Orazem and Mattila utilized information on successive cohorts of Maryland high school graduates to study how changes in the relative variance of occupational earnings altered occupational and educational choices. To our knowledge, no one has conducted a similar empirical study of how variation in health risks affects occupational choice.
}

Davis, J.U., J.A. Caswell, and C.R. Harper. "Incentives for Protecting Farm Workers from Pesticides." Amer. J. Agr. Econ. 74(November 1992):907-17.

Donham, K.J., S.J. Reynolds, P. Whitten, J.A. Merchant, L.F. Burmeister, and W.J. Popendorf. "Respiratory Dysfunction in Swine Production Workers: Dose-response Relationship of Environmental Exposures and Pulmonary Function." Am. J. Ind. Med. 27(1995):405-18.

Frisvold, G., R. Mines, and J.M. Perloff. "The Effect of Job Site Sanitation and Living Conditions on the Health and Welfare of Agricultural Workers." Amer. J. Agr. Econ. 70(August 1988):875-85.

Harper, C.R., And D. Zilberman. "Pesticide and Worker Safety." Amer. J. Agr. Econ. 74(February 1992):68-78.

Hersch, J., and W.K. Viscusi. "Cigarette Smoking, Seatbelt Use, and Differences in WageRisk Tradeoffs." J. Human Resour. 25(Spring 1990):202-27.

Holness, D.L., E.L. O’Glenis, A. Sass-Kortsak, C. Pilger, and J. Nethercott. "Respiratory Effects and Dust Exposures in Hog Confinement Farming." Am. J. Ind. Med. 11(1987):571-80.

Hurley, T.H., P.F. Orazem, and J. Kliebenstein. "Structure of Wages and Benefits in the U.S. Pork Industry." Amer. J. Agr. Econ. 81(February 1999):144-63.

Iowa Farm Costs and Returns-1995, Iowa Coop. Ext. Serv., Publ. FM-1789, 1996.

Miller, A. Pulmonary Function Tests in Clinical and Occupational Lung Disease. Orlando FL: Grune and Stratton, 1986.

Orazem, P.F., and J.P. Mattila. "Human Capital, Uncertain Wage Distributions, and Occupational and Educational Choices." Int. Econ. Rev. 32(February 1991):103-22.

Pingali, P.L., C.B. Marquez, and F.G. Palis. "Pesticides and Philippine Rice Farmer Health: A Medical and Economic Analysis." Amer. J. Agr. Econ. 76(August 1994):587-92.

Reynolds, S.J., K.J. Donham, P. Whitten, and J.A. Merchant. "A Longitudinal Evaluation of Dose-Response Relationships for Environmental Exposures and Pulmonary Function in Swine Production Workers." Am. J. Ind. Med. 29(1996):33-40. 